\title{
The challenges of metabolic disorders in Indonesia: focus on metabolic syndrome, prediabetes, and diabetes
}

Ketut Suastika

The report from Global Health Metrics based on the Global Burden of Disease Study 2019 stated that diabetes is the eighth leading cause of disabilityadjusted life years in all ages. ${ }^{1}$ In Indonesia, the cause of death has changed in the last 10 years. Diabetes itself has shifted up from the $6^{\text {th }}(2009)$ to the $3^{\text {rd }}(2019)$ rank of cause of death. Moreover, regarding both the cause of death and disability, the top four ranks were stroke, ischemic heart disease, neonatal disorders, and diabetes mellitus (DM). ${ }^{2}$ It is already well known that insulin resistance-related disorders, such as obesity, metabolic syndrome (MetS), prediabetes, and DM, are the prominent risk factors in cardiovascular diseases (CVDs).

\section{Metabolic syndrome (MetS)}

MetS is a cluster of metabolic disorders, which has three potential etiological categories: obesity and disorders of adipose tissue; insulin resistance; and a constellation of independent factors (e.g., molecules of hepatic, vascular, and immunologic origin). ${ }^{3}$ Diagnosis of MetS is confirmed based on the criteria of a Joint Interim Statement of International Diabetes Federation (IDF), NIH, AHA, WHF, IAS, and IASO (2009). MetS is diagnosed if three or more of the following five criteria are present: elevated waist circumference (male $>90 \mathrm{~cm}$; female $>80 \mathrm{~cm}$ ); elevated triglycerides level (drug treatment for elevated triglycerides is an alternate indicator; $\geq 150 \mathrm{mg} / \mathrm{dl}$ ); reduced high-density lipoprotein (HDL) cholesterol level (drug treatment for reduced HDL cholesterol is an alternate indicator; $\leq 40 \mathrm{mg} / \mathrm{dl}$ in males and $\leq 50 \mathrm{mg} / \mathrm{dl}$ in females); elevated blood pressure (antihypertensive drug treatment in a patient with a history of hypertension is an alternate indicator; systolic pressure $\geq 130$ and/or diastolic pressure $\geq 85 \mathrm{~mm} \mathrm{Hg}$ ); elevated fasting glucose level (drug treatment of elevated glucose is an alternate indicator; $\geq 100 \mathrm{mg} / \mathrm{dl}) .^{4}$
The prevalence of MetS in Indonesia varies in different studies. MetS is influenced by the subjects, location, and time of study. Suastika et al ${ }^{5}$ reported $18.2 \%$ in Bali and Soewondo et al ${ }^{6}$ reported $28.4 \%$ in Jakarta. Meanwhile Sigit et $\mathrm{al}^{7}$ reported $28 \%$ in men and $46 \%$ in women (compared with $36 \%$ and $24 \%$ in Dutch men and women) based on the Indonesian Basic Health Research 2013 data. Each component of the MetS is an independent risk factor for CVD, and the combination of these risk factors rises the rates and severity of CVD, related to a spectrum of cardiovascular conditions including microvascular dysfunction, coronary atherosclerosis and calcification, cardiac dysfunction, myocardial infarction, and heart failure. ${ }^{8}$ In a cohort study, enrolling 3,323 middle-aged adults, it was found that, in men, the MetS age-adjusted relative risk (RR) was 2.88 for CVD, 2.54 for coronary heart disease (CHD), and 6.92 for type 2 diabetes mellitus (T2DM). Event rates and RRs were lower in women for CVD ( $R R=2.25)$ and $C H D(R R=1.54)$, but they were similar for T2DM $(R R=6.90)$. Populationattributable risk estimates associated with MetS for CVD, CHD, and T2DM were $34 \%, 29 \%$, and $62 \%$ in men and $16 \%, 8 \%$, and $47 \%$ in women. ${ }^{9}$ The high prevalence of MetS in Indonesia may contribute to the increase of the prevalence of DM and CVD since MetS itself is a common risk factor for DM and CVD.

\section{Prediabetes and diabetes}

DM is a chronic progressive metabolic disease characterized by hyperglycemia, and its main mechanisms are a insulin resistance and an insufficient insulin secretion by beta cells. DM is diagnosed by findings of classical clinical features and confirmed by measuring of plasma glucose level. Prediabetes, a phase between normoglycemia and DM, is defined by impairment of fasting or postprandial glucose levels after glucose loading, named impaired fasting 


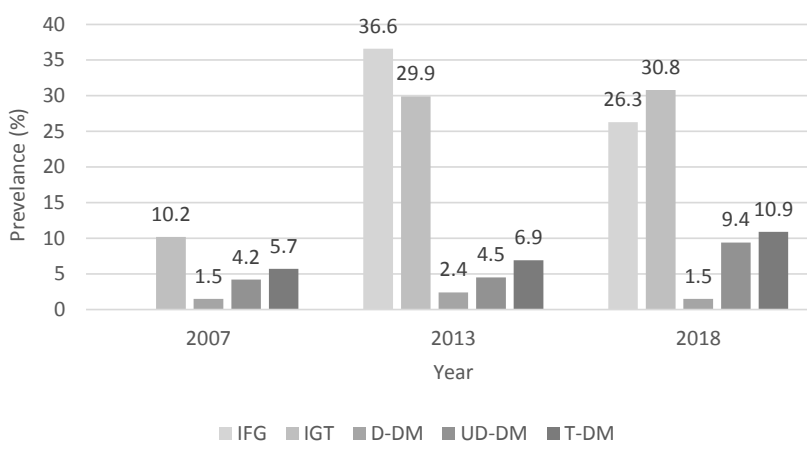

Figure 1. Prevalence of IFG, IGT, and DM in adults. No data of IFG in 2007. IFG=impaired fasting glycemia; IGT=impaired glucose tolerance; D-DM=diagnosed diabetes; UD$\mathrm{DM}=$ undiagnosed diabetes; T-DM=total diabetes. Data from Basic Health Research (RISKESDAS), 2007, 2013, and 2018. Ministry of Health of the Republic of Indonesia: National Institute of Health Research and Development, 2007, 2013, and 2018

glycemia (IFG) and impaired glucose tolerance (IGT), respectively.

Based on the data from the Indonesian Basic Health Research in 2007, 2013, and 2018, the prevalence of prediabetes and DM in adults was a sharply increased prevalence of DM in 10 years, and more than two-thirds of people with DM were actually undiagnosed (Figure 1). ${ }^{10-12}$ IDF Atlas (2019) has noticed that Indonesia has 29 million patients with IGT and has become one of the top three countries having patients with IGT after China and the United States of America. Indonesia ranks seventh among the top 10 countries with the largest number of adults with DM, that is, 10.7 million people. ${ }^{13}$ Da Qing Diabetes Prevention Study showed that, without intervention, $65.8 \%$ of patients with IGT developed diabetes in 6 years. ${ }^{14} \mathrm{~A}$ study on the progression of DM from prediabetes in Bogor showed that IFG, IGT, and a mix of IFG+IGT progressed to DM in $6.21,6.12$, and 14.6 per 100 persons/year, respectively. Risk factors for T2DM development in the study are age (40-54 years, $R R=1.97 ; 55-65$ years, $R R=2.74$ ), central obesity $(R R=4.42)$, hypertension $(R R=1.99)$, and hypertriglyceridemia $(R R=1.83) .15$

Talking about the glycemic goal, several studies in Indonesia revealed that only around one-third of DM patients achieved the glycemic target of hemoglobin A1c (HbA1c) $<7 \%$ (mean HbA1C $=8.27 \%, \mathrm{HbA} 1 \mathrm{c}<7 \%=34 \%$ in International Diabetes Management Practice Study 2006-2007 ${ }^{16}$; mean $\mathrm{HbA} 1 \mathrm{C}=8.16 \%$, $\mathrm{HbA} 1 \mathrm{C}<7 \%=32 \%$ in DiabCare 2008 ${ }^{17}$; mean HbA1c $=8.3 \%$, $\mathrm{HbA} 1 \mathrm{c}<7 \%=31 \%$ in DiabCare 2012 ${ }^{18}$; and median $\mathrm{HbA} 1 \mathrm{C}=8.3 \%$, HbA1c $<7 \%$ $=28.2 \%$ in TANDEM Consortium ${ }^{19}$ ). Failure to achieve the glycemic goal among people with DM may result from clinical inertia due to patients' poor compliance, physicians unwilling to adjust the therapy, and/or low accessibility to healthcare services. Poor glycemic control will result in chronic complications, especially macro- and microvascular diseases, and also lead to a socioeconomic burden for both the patients and their families and the government. Results from DISCOVER Study showed that Indonesia has a high prevalence of both micro- and macrovascular complications related to very poor glycemic control compared with other countries. $^{20}$

\section{The role of Indonesian Society of Endocrinology (InaSE) and government}

InaSE is a professional organization of physicians with expertise or interest in endocrinology, metabolism, and diabetes. The main task of InaSE is educating physicians and paramedics and the public, besides leading and proposing researches and international publications. To achieve this, InaSE has collaborated with many parties, governmental and nongovernmental organizations, national and international professional organizations. In prevention and management of DM, InaSE has trained more than 15,000 physicians (general practitioners [GPs] and specialists) through several programs such as Partnership for Diabetes Control in Indonesia (20122016), Diabetes Education Enhancement for Engaged Partnership (2017-present), INSPIRE (2012-2016), APPROVE (2019-2020), and ASCEND (2018-2019). Guideline for Diabetes Management in Indonesia $(2019)^{21}$ and InaSE Statement on Diabetes Management during COVID-19 (2020) ${ }^{22}$ had also been published and became a guidance for GPs and specialists in daily practice. Other guidelines and textbooks related to metabolic diseases management published in 2019 were Guideline for Self-Monitoring Blood Glucose, Guideline for Management of Dyslipidemia in Indonesia, Guideline for Insulin Therapy in Patient with Diabetes Mellitus, Guideline for Management of Hyperglycemia in Pregnancy, and Capita Selecta of Clinical Thyroidology.

Obesity, MetS, and prediabetes are important risk factors for DM and CVD. Currently, InaSE has not developed a specific program for combating them. However, their management belongs to the primary prevention of DM, which has been generally explained in our guidelines. Recently, InaSE is supporting the 
Ministry of Health to develop a program to manage prediabetes. The Ministry of Health will soon introduce and implement prediabetes management programs at the primary care level through a cadre of Pos Pembinaan Terpadu (Posbindu) and primary care physicians (at primary healthcare facilities). In the future, InaSE will be involved consistently in education, covering a greater number of healthcare providers and focusing on primary prevention; conducting more research development; collaborating with both national and international organizations or professions; supporting the government to develop and implement programs, proposals, and approval of new drugs; supporting higher education to develop curriculums on endocrinology, metabolism, and diabetes; spreading awareness about metabolic diseases.

The chronic care model (CCM) is a comprehensive model about how to take care of patients with chronic diseases such as DM and to achieve better functional and clinical outcomes, by ensuring productive interactions between an informed, activated patient and a proactive prepared practice team. CCM defines six domains that require attention to optimize outcomes: delivery system design, self-management support, clinical information systems, decision support, community, and health system-related issues. ${ }^{23}$ The care model has been adopted and implemented in many countries. Since Indonesian national coverage (National Health Insurance or Jaminan Kesehatan Nasional) has been implemented in 2014, diabetes, and especially its complications, has attracted a special attention not only related to the high morbidity and mortality, but also the high cost needed for management. Empowering primary care services to screen and manage people with prediabetes and DM adequately to prevent complications needs to be our priority. Indonesian Ministry of Health has a similar care program for patients with DM and hypertension, namely, CCM (Pengelolaan Penyakit Kronis [Prolanis]). Prolanis is not running perfectly yet and covers only a small portion of patients with DM and hypertension in Indonesia.

Although significant effort has been made by both governmental and nongovernmental organizations, in reality, the prevalence and impact of prediabetes and DM are increasing. Therefore, we need breakthrough programs for a comprehensive healthcare system that manages catastrophic chronic diseases such as DM and its risk factors, which focus on primary and secondary prevention through education, promotion, and improvement of healthcare service accessibility to reverse prediabetes to be normoglycemia and lower the prevalence of DM and its complications.

\section{Summary}

In Indonesia, the current and future challenges of MetS, prediabetes, and DM are as follows: (1) the prevalence and number of adults with MetS, prediabetes, and DM are high with an increasing trend; (2) if this was not managed well, the high prevalence of prediabetes will eventually lead to elevated DM and CVD events; (3) more than twothirds of people with DM are undiagnosed, which means that most of them will potentially present to a clinic or hospital with advanced complications; (4) many patients have poor adherence, and therefore more than two-thirds of patients with diabetes do not achieve glycemic targets; (5) DM-related macro- and microvascular complications are high; (6) managing diabetes and its complications requires great costs, but the government's budget is limited. Breakthrough programs for a comprehensive healthcare system offering chronic care management may be needed to be implemented in the future.

From Indonesian Society of Endocrinology, Jakarta, Indonesia; Faculty of Medicine, Universitas Udayana, Sanglah General Hospital, Denpasar, Indonesia

pISSN: 0853-1773 • eISSN: 2252-8083

https://doi.org/10.13181/mji.com.205108

Med J Indones. 2020;29:350-3

Corresponding author:

Ketut Suastika

E-mail: ksuas@unud.ac.id

\section{REFERENCES}

1. GBD 2019 Diseases and Injuries Collaborators. Global burden of 369 diseases and injuries in 204 countries and territories, 19902019: a systematic analysis for the Global Burden of Disease Study 2019. Lancet. 2020;396(10258):1204-22.

2. Institute for Health Metrics and Evaluation. Indonesia [Internet]: Seattle University of Washington; [cited 2020 Oct 16]. Available from: http://www.healthdata.org/indonesia.

3. Grundy SM, Brewer Jr HB, Cleeman JI, Smith Jr SC, Lenfant C. Definition of metabolic syndrome: report of the National Heart, Lung, and Blood Institute/American Heart Association conference on scientific issues related to definition. Circulation. 2004;109(3):433-8.

4. Alberti KG, Eckel RH, Grundy SM, Zimmet PZ, Cleeman JI, Donato $K A$, et al. Harmonizing the metabolic syndrome: a joint interim statement of International Diabetes Federation, National Heart Lung and Blood Institute; American Heart Association; World Heart Federation; International Atherosclerosis Society and International Association for the Study of Obesity. Circulation. 2009;120(16):1640-5. 
5. Suastika K, Dwipayana P, Saraswati IMR, Gotera W, Gde Budhiarta AA, Dwi Sutanegara IN, et al. Prevalence of obesity, metabolic syndrome, impaired fasting glycemia, and diabetes in selected villages of Bali, Indonesia. ASEAN Fed Endocr Soc. 2011;26(2):159-62.

6. Soewondo P, Purnamasari D, Oemardi M, Waspadji S, Soegondo S. Prevalence of metabolic syndrome using NCEP/ATP III criteria in Jakarta, Indonesia: the Jakarta primary non-communicable disease risk factors surveillance 2006. Acta Med Indones. 2010;42(4):199-203.

7. Sigit FS, Tahapary DL, Trompet S, Sartono E, Willems van Dijk $\mathrm{KW}$, Rosendaal FR, et al. The prevalence of metabolic syndrome and its association with body fat distribution in middle-aged individuals from Indonesia and the Netherlands: a crosssectional analysis of two population-based studies. Diabetol Metab Syndr. 2020;12:2.

8. Tune JD, Goodwill AG, Sassoon DJ, Mather KJ. Cardiovascular consequences of metabolic syndrome. Trans Res. 2017;183:5770.

9. Wilson PW, D’Agostino RB, Parise H, Sullivan L, Meigs JB, Metabolic syndrome as a precursor of cardiovascular disease and type 2 diabetes mellitus. Circulation. 2005;112(20):3066-72.

10. Ministry of Health of The Republic of Indonesia. Basic Health Research (RISKESDAS) 2007. Ministry of Health of the Republic of Indonesia: National Institute of Health Research and Development; 2007. Indonesian.

11. Ministry of Health of The Republic of Indonesia. Basic Health Research (RISKESDAS) 2013. Ministry of Health of the Republic of Indonesia: National Institute of Health Research and Development; 2013. Indonesian.

12. Ministry of Health of The Republic of Indonesia. Basic Health Research (RISKESDAS) 2018. Ministry of Health of the Republic of Indonesia: National Institute of Health Research and Development; 2018. Indonesian.

13. International Diabetes Federation. IDF Diabetes Atlas. 9th ed: Brussel: International Diabetes Federation; 2019.

14. Li G, Zhang P, Wang J, Gregg EW, Yang W, Gong Q, et al. The long-term effect of lifestyle interventions to prevent diabetes in the China Da Qing Diabetes Prevention Study: a 20-year followup study. Lancet. 2008;371(9626):1783-89.

15. Sulistiowati E, Sihombing M. Progression of type 2 diabetes mellitus from prediabetes at Bogor, West Java. J Pen Pengemb Pel Kes. 2018;2(1):59-69. Indonesian.

16. Soewondo P. Current practice in the management of type 2 diabetes in Indonesia: results from the International Diabetes Management Practice study (IDMPS). J Indon Med Assoc. 2011;61(12):474-81.

17. Soewondo P, Soegondo S, Suastika K, Pranoto A, Soeatmadji DW, Tjokroprawiro A. The DiabCare Asia 2008 Study - outcomes on control and complications of type 2 diabetic patients in Indonesia. Med J Indones. 2010;19(4):235-44.

18. Cholil AR, Lindarto D, Pemayun TGD, Wisnu W, Kumala P, Puteri HHS. DiabCare Asia 2012: diabetes management, control, and complications in patients with type 2 diabetes in Indonesia. Med J Indones. 2019. 28(1):47-56.

19. Soetedjo NNM, MCAllister SM, Ugarte-Gil C, Firanescu AG, Ronacher K, Alisjahbana B, et al. Disease characteristics and treatment of patients with diabetes mellitus attending government health services in Indonesia, Peru, Romania and South Africa. Trop Med Int Health. 2018;23(10):1118-28.

20. Kosiborod M, Gomes MB, Nicolucci A, Pocock S, Rathmann $\mathrm{W}$, Shestakova MV, et al. Vascular complications in patients with type 2 diabetes: prevalence and associated factors in 38 countries (the DISCover study program). Cardiovasc Diabetol. 2018;17(1):150.

21. Indonesian Society of Endocrinology. Guidelines for the Management and Prevention of Type 2 Diabetes Mellitus in Adults in Indonesia: Indonesian Society of Endocrinology; 2019.

22. Indonesian Society of Endocrinology (ISE). Position statement on how to manage patients with diabetes and COVID-19. J ASEAN Fed Endocr Soc. 2020;35(1):49-51.

23. Stuckey HL, Adelman AM, Gabbay RA. Improving care by delivering the chronic care model for diabetes. Diabetes Manag. 2011;1(1):37-52. 